Stefanie Seifert, Eva Schlenker*

\title{
Occupational segregation and organizational characteristics. Empirical evidence for Germany
}

This article studies the extent of occupational gender segregation in Germany and analyzes the influence of organizational characteristics on the extent of firm level segregation. We use the 2004 and 2008 survey waves of the Linked-Employer-Employee dataset at the IAB (LIAB) and estimate panel data models for the identification of effects on the corrected dissimilarity index. We find that the link between the level of segregation and organizational characteristics such as gender mainstreaming, formalization and the proportion of women in management positions depends on features of organizational demographics. The results can be utilized by businesses and politics to identify levers for the reduction of segregation.

Key words: gender segregation, panel data models, dissimilarity index, gender inequality (JEL: C23, J10, J16, J24, M50)

* Stefanie Seifert, University of Tübingen, Faculty of Economics and Social Sciences, Statistics, Econometrics and Quantitative Methods, Mohlstr. 36, 72074 Tübingen, Germany. E-mail: stefanie.seifert@uni-tuebingen.de.

Dr. Eva Schlenker, University of Hohenheim, Faculty of Business, Economics and Social Sciences, Statistics \& Econometrics I, 70593 Stuttgart, Germany.

E-mail: eva.schlenker@uni-hohenheim.de.

** Article received: October 31, 2013

Revised version accepted after double blind review: October 22, 2014. 


\section{Introduction}

Occupational gender segregation, i.e. the unequal distribution of men and women across areas and positions on the labor market, is a well-documented phenomenon. A relatively high and stable level of segregation could be confirmed for the German labor market, particularly in comparison with other European countries (e.g. European Commission [EUCOM], 2010). The stability of segregation at labor market level can be observed despite the equalization of women and men in many respects in and around the labor market, for example in the level of training and labor market participation (inter alia Jürges \& Schneider, 2011). From the supply side, different job preferences seem to explain segregation; however, the demand side of the labor market can also be examined as another potential source of segregation, which is why we put the firm at the center of our study. The fact that there are significant differences in the level of segregation within individual firms indicates that business characteristics can play a role when it comes to segregation in the labor market. With a joint analysis of the level of segregation and organizational characteristics we hope to identify levers that can facilitate the reduction of segregation. Identifying these levers is particularly interesting because segregation reflects a dimension of social inequality. Segregation can be seen as a problem of equal opportunities between genders: The separation based on jobs and job positions goes hand in hand with different entry and career opportunities as well as remuneration. Yet gender parity among employees is not only a question of equal opportunities and consequently of political and social relevance, but it can also be a factor of economic interest for companies. That is the case when we assume an increase in productivity with mixed-gender workgroups, as experimental and empirical studies have shown (cf. e.g. Lee \& Farh, 2004). Our paper studies the factors influencing the level of occupational gender segregation in German firms, based on the 2004 and 2008 survey waves of the Linked-Employer-Employee dataset at the IAB (LIAB). The relationship between the extent of firm level segregation and organizational characteristics - such as business size, industry, or organizational demographics - has its theoretical foundation in organizational sociology (see Acker, 1990) as well economic approaches, such as the theory of statistical discrimination (an overview of approaches from organizational theory can be found in e.g. Achatz, 2008). Empirical evidence for the German labor market can be found among others in Achatz, Beblo, and Wolf (2010) or Hinz and Schübel (2001). The aim of our contribution is first of all to verify the relationships found in these studies using more current data and to extend the econometric models to other explanatory factors. The data structure of the LIAB allows us to carry out panel estimations for the level of segregation and to control them for numerous organizational characteristics. Our focus of interest is to examine the relationship between measures of gender mainstreaming and formalized recruitment procedures and the extent of segregation within establishments. By studying these two potential influencing factors we can show whether there is a systematic connection between measures in the field of human resources and organization and the internal level of segregation in the company. Our paper also considers a new aspect of modeling the interdependent effect of the proportion of parttime positions and of women in the workforce. So far no significant influence of the 
proportion of part-time positions has been found in studies (e.g. Achatz et al., 2010). We assume, however, that this effect only becomes significant in connection with the proportion of women in the workforce and consider this in our estimations. To our knowledge this relationship has not yet been empirically researched.

This article is structured as follows: Section two provides an overview of the theoretical background as well as the present state of research on horizontal segregation. The third section explains possibilities for measuring horizontal segregation and the applied econometric methods. Section four introduces the data that has been utilized. The fifth section presents the findings regarding the extent of horizontal gender segregation as well as the results of the estimations. Section six concludes with a summary.

\section{The current research landscape}

Gender segregation in the labor market describes the distribution of men and women across occupations or occupational positions. Two dimensions can be distinguished horizontal and vertical segregation - and different levels can be defined (cf. e.g. Blackburn, Browne, Brooks, \& Jarman, 2002). Horizontal segregation describes the distribution of men and women across different firms, occupations, or industries; however, the hierarchical level or the degree of responsibility is not considered. Measured at labor market level it demonstrates to what extent the gender ratio of the labor market is reflected in the individual professions. In contrast, segregation within the workforce can be interpreted as a difference in opportunity structures inside a company (cf. Handl, 1984).

Vertical segregation as the second dimension of segregation refers to the corporate rank hierarchy of employees, which depicts the gender inequality that comes along with higher income and differences in organizational power (cf. e.g. Allmendinger \& Podsiadlowski, 2001). In this article we focus on the analysis of the extent of horizontal segregation choosing the firms as the unit of analysis. Aspects of vertical segregation are incorporated as potential explanatory factors.

When explaining the emergence of segregation the theoretical approaches can be divided into supply-side and demand-side theories: Supply-oriented explanations claim that horizontal gender segregation can be attributed to individual characteristics, prejob constellations (outside the working world) as well as different preferences between the sexes. Approaches are, for example, the theories of human capital or socialization. In contrast, demand-side approaches emphasize the effectiveness of social control mechanisms, structural constraints and barriers on the level of the labor market that make it more difficult for women to enter professions dominated by men. Moreover, it is implied that employers practice discrimination and personnel selection, hampering the entry of women into professions dominated by men and vice versa (for an overview see Busch, 2013).

Apart from the role of the employer, demand-side approaches stress the organizations role as a social unit. This requires taking a firm-level perspective, which in the field of segregation research has mostly been neglected in previous studies. The starting point is to regard organizations as corporate actors that employ men and women 
for certain positions, open up career opportunities and show preferences for a genderspecific selection of staff for their positions (cf. Bielby \& Baron, 1980).

So far, numerous empirical studies have analyzed - in the tradition of organizational theory - the relationship between different organizational characteristics and the extent of occupational segregation. One of the most widely discussed impacting factors is the size of the company, measured by the number of employees. A higher number of employees goes hand in hand with the implementation of a human resource policy, e.g. the formalization of recruitment procedures, which impedes discrimination based on gender. In addition, gender-homogenous recruitment simply becomes more difficult as the size of the company increases (cf. e.g. Tomaskovic-Devey \& Skaggs, 2001). For German establishments Hinz and Schübel (2001) have shown that the number of employees has a significantly negative influence on the extent of occupational gender segregation.

There is also empirical evidence for the influence of organizational demographics, i.e. the structure of the workforce, on the level of segregation within a firm with a particular focus on the gender ratio of the staff. Utilizing German data Achatz et al. (2010) have initially found a negative effect of the proportion of women in the workforce (cf. also Achatz, 2008; Allmendinger \& Podsiadlowski, 2001; Beblo, Heinze \& Wolf, 2008 as well as Bansak et al., 2012 for effects at labor market level in the USA). This can be interpreted as an indication that men have easier access to professions dominated by women, while the male-dominated occupational fields have strong barriers to entry for women (cf. Achatz et al., 2010). It can be assumed that further diversity categories apart from gender are connected with segregation (cf. theories on intersectionality, e.g. Siebert \& Bornheim, 2011). In our analysis, we consider the age structure of the workforce. This is based on the theoretical assumption that an older workforce might have a higher proportion of men, as there have historically been more men than women in the labor market. Moreover, it can be argued that the employment behavior of women has changed significantly in the past years and that it can therefore be assumed that women starting their work life today or who have started their work life a few years before tend to fill more full-time positions in comparison with older women. The proportion of part-time employees is another characteristic feature of the workforce whose influence on the level of segregation is theoretically discussed. A high proportion of part-time employment can be seen as an opportunity enabling women to enter male-dominated occupational fields. However, Achatz et al. (2010) are not able to show significant effects. We assume that the direction of the effect depends on other variables of organizational demographics. Instead of providing entry opportunities to women, the offer of part-time work in an environment already dominated by women might actually enforce segregation, as there is no "lead in" for men. So the direction of effect of the share of part-time positions changes depending on the proportion of women in the workforce (cf. Allmendinger \& Podsiadlowski, 2001). We model this moderating effect on the mechanism by considering the interdependence of the proportion of women and the share of part-time positions with regard to the respective workforce in our empirical model. Empirical studies have also shown that a firm's legal form influences the level of segregation: For corporations under public law in Germany a higher degree of formalization can be expected, lead- 
ing to lower segregation on average, as a discriminating recruitment policy is more difficult to maintain (cf. Achatz et al., 2010). It can also be argued that because of the different legal conditions, the exogenous pressure on the organization that arises varies in strength. By analogy to this statement we will also explain the results that in younger firms an integrated structure of the workforce is more likely. The age of the organization is assumed as an influencing factor, as younger firms are exposed to particularly strong legal and social pressure when it comes to gender equality (cf. TomaskovicDevey \& Skaggs, 2001 for the USA). Moreover, there is international evidence that the industry in which a company operates can be taken into account as another distinguishing feature for the extent of occupational segregation (among others Organisation for Economic Cooperation and Development [OECD], 2012). The varying distribution of men and women across different occupational fields and moreover different corporate cultures within the industries is seen as the reason. Additionally, a particularity of German studies is the location in Germany as an influencing factor on the extent of segregation. Many studies have provided empirical evidence for the differences between West and East German firms indicating a higher level of segregation in East Germany (e.g. Falk, 2002; Trappe \& Rosenfeld, 2001). For the time immediately after reunification, a higher level of segregation in East Germany can be interpreted as a result of the state-controlled labor force distribution of the former GDR, where despite high female employment, women preferred to work in occupational fields typically occupied by females than their counterparts in West Germany (cf. Busch, 2013). The fact that these differences increased initially after reunification and have remained consistent up to today, is connected to the decline of the proportion of women in total employment in East Germany and implies transformation-related reasons in the form of changes in the occupational structure (cf. Falk, 2002).

There is empirical evidence for the factors influencing the extent of occupational gender segregation that have been pointed out so far, particularly also for the German labor market, and they are therefore included in our analysis as control variables. In contrast, less attention has been paid to the relationship between segregation and formalized recruitment processes as well as equality policies, presumably because of the limited availability of data. At the international level, the studies of Stainback and Kwon (2012) and Tomaskovic-Devey and Skaggs (2001) have analyzed the effects of formalized processes in organizations. They find that formalization - under certain conditions - can promote a balanced gender distribution. Theoretical works argue: The less formalized organizational routines are, the more room there is for "cronyism, subjectivism, sex stereotyping and bias" (Reskin \& McBrier, 2000: 214) in recruitment processes, job assessment, or in promotion. The implementation of active gender mainstreaming measures can be part of a formalized personnel routine, but also an independent factor. In their study, Stainback and Kwon (2012) show a negative effect of equal opportunity measures on horizontal segregation in least square regressions based on South Korean data. The link between the implementation of gender mainstreaming and less horizontal segregation in Germany, also results from the bivariate analysis carried out by Beblo et al. (2008). Achatz et al. (2010) assume a causal relationship. However, the authors cannot verify this empirically as their analysis is based on data without information on whether gender equality policies exist. We close this research 
gap and use other waves of the same dataset for our analysis, which include variables for the implementation of gender mainstreaming. By using these waves of the LIAB, we are also able to identify the degree of formalization in organizations and to analyse its effect on the extent of firm level gender segregation. Using American data, Tomaskovic-Devey and Skaggs (2001) analyze the influence of bureaucracy. They find that bureaucratization in general does not lead to a reduction of segregation, but that the direction of effect depends on other organization-specific variables, e.g. management culture. A corresponding interdependence of formalization and other organizational characteristics for Germany is also assumed by Allmendinger and Podsiadlowski (2001). We will empirically consider the interaction of the gender ratio in the workforce and the degree of formalization.

Another determinant of the level of occupational segregation, which from our point of view has not yet been studied sufficiently, is vertical segregation. Stainback and Kwon (2012) have also analyzed this connection and find a positive relationship for South Korean data. As we assume a connection between horizontal and vertical segregation (cf. Blackburn et al., 2002), the exact direction of effect is theoretically not clear and should be analyzed in experimental studies. It is possible that the gender ratio in the leadership structures has an effect on horizontal segregation, or that horizontal segregation entails inequalities in the vertical dimension. The latter is based on the assumption that when men and women do not work in the same professions, wage discrimination is easier with equal work performance than with work in comparable fields (cf. Ludsteck, 2014). We include the share of women in management positions as an explanatory factor of occupational horizontal segregation.

In addition, further research in the field of gender segregation refers to the empirical survey of supply-side theories as well as studies on the effects, such as the Gender Pay Gap (e.g. Busch, 2013; Hinz \& Gartner, 2009).

\section{Determining the extent of gender segregation and its influencing factors}

\subsection{Calculation and correction of the dissimilarity index}

In order to gather and quantify the gender-related segregation in the labor market, various concepts exist for the operationalization and measurement of the unequal distribution of the sexes across occupations. Segregation indices constitute one possibility of condensing the extent of segregation to a single key figure. The existing literature on index measures of occupational segregation is comprehensive and offers numerous approaches (for an overview see Flückiger \& Silber, 1999). For this article, we decided on the dissimilarity index by Duncan and Duncan (1955). This captures on the one hand the horizontal dimension that we are interested in, and it is on the other hand in widespread use in the current literature, which facilitates the comparison of our results.

The dissimilarity index at total labor market level is defined as

$D I=\frac{1}{2} \sum_{j}\left|\frac{F_{j}}{F}-\frac{M_{j}}{M}\right| \quad$ with $\mathrm{j}=1, \ldots$, m occupations, 
where $F_{j}$ states the number of women in occupation $j, M_{j}$ the number of men in occupation $j$ and $F$ the number of females and $M$ the number of males on the labor market. For the calculation of the value at establishment level $\left(\mathrm{DI}_{\mathrm{i}}\right)$ we adapt the formula. The segregation within an establishment is calculated as

$$
D I_{i}=\frac{1}{2} \sum_{j}\left|\frac{F_{i j}}{F_{i}}-\frac{M_{i j}}{M_{i}}\right| \text { with } \mathrm{i}=1, \ldots, \mathrm{n} \text { establishments and } \mathrm{j}=1, \ldots, \mathrm{m} \text { occupations, }
$$

whereby the size of the workforce is chosen as the reference value, thus $F_{i j}\left(M_{i j}\right)$ stands for the number of females (males) in firm $i$ and profession $j$ and $F_{i}\left(M_{i}\right)$ for the number of females (males) in firm $i$. In order to receive a meaningful value for the whole of Germany, the index values are averaged over all firms using weighting factors. ${ }^{1}$

The dissimilarity index is normalized to the interval [1;0], with the value 0 showing that the same gender ratio can be found in all professions. The value 1 indicates complete segregation, i.e. in each profession there are either only women or only men (cf. Duncan \& Duncan, 1955).

A disadvantage of the dissimilarity index is that, in firms where certain professional groups are poorly occupied, a strong segregation can be measurable even with a random distribution of men and women (with the given gender ratio of the workforce). To account for that we use a corrected version of the dissimilarity index by Carrington and Troske (1997). Based on random distribution, a hypothetical index value DI*, dependent on the number of employees for a given size of the professional group, is initially simulated. The corrected dissimilarity index $\left(D I_{\text {cor }}\right)$ then results from the deviation of the measured value to the hypothetical value and is defined in the interval $[-1 ; 1]$ :

$D I_{c o r}=\left\{\begin{array}{lll}\frac{D I-D I^{*}}{1-D I^{*}} & \text { for } & D I \geq D I^{*} \\ \frac{D I-D I^{*}}{D I^{*}} & \text { for } & D I<D I^{*}\end{array}\right.$

We calculate the corrected index first at the level of the labor market $\left(\mathrm{DI}_{\text {cor }}\right)$ and also individually for each establishment $\left(\mathrm{DI}_{\mathrm{i}, \mathrm{cor}}\right)$. This correction allows us to capture the systematic extent of horizontal segregation. Random influences are controlled and no longer lead to an overestimation of the actual extent of segregation.

\subsection{Estimation and identification strategy}

The aim of this study is to describe not only the extent of gender segregation in German firms and on the labor market as a whole, but most importantly the influence of organizational characteristics. To check for unobserved heterogeneity at company lev-

1 For descriptive statistics on $\mathrm{DI}_{\mathrm{i}}$ we use the weighting factors of the cross-sectional data provided by the IAB establishment panel. These weighting factors are necessary as the $\mathrm{IAB}$ establishment panel is based on a multiply disproportionate sample regarding the characteristics establishment size, industry, and federal state. 
el, we make use of the panel structure of the LIAB and utilize the data of the survey waves from the years 2004 and 2008 to carry out different panel estimations. We estimate a model of the following form

$$
\begin{aligned}
& D I_{\text {COR }_{i t}}=\gamma_{i}+\beta_{1} \text { formalism }_{i t}+\beta_{2} \text { formalism }_{i t} * F S_{i t}+\beta_{3} \text { gendermainstr }_{i t} \\
& +\beta_{4} \text { gendermainstr } r_{i t} * F S_{i t}+\beta_{5} P T Q_{i t}+\beta_{6} P T Q_{i t} * F S_{i t}+\beta_{7} F S_{i t} \\
& +\beta_{8} \text { top }_{\text {share }} \text { it }+\beta_{9}\left(\text { top share } \text { sit }^{2}+\beta_{10}\left(\text { top }_{\text {share }}\right)^{3}+X_{i t} \alpha+u_{i t}\right.
\end{aligned}
$$

DI $_{\text {CORit }}$ marks the corrected dissimilarity index as described in Chapter 3.1 in establishment $i$ at the time $t$, which is normalized to a [0;1] interval. ${ }^{2}$

Formalism $_{\text {it }}$ and measure ${ }_{i t}$ are dummy variables that take the value 1 if establishment $i$ at the time $t$ uses formalized recruitment procedures or applies measures promoting the equality of men and women. $F S_{i t}$ marks the female share in the workforce of establishment $i$ at the time t. PTQ $Q_{i t}$ denotes the proportion of part-time employees in establishment $i$ at the time $t$. Top share it refers to the share of women in top management positions in establishment $i$ at the time $t$. Vector $\mathrm{X}_{\mathrm{it}}$ comprises the control variables proportion of women in establishment, location (East / West Germany), age of organization, ${ }^{3}$ number of employees (logarithmized), year, number of employees with university degree, number of women in establishment with university degree, number of employees typical in male / female professions, ${ }^{4}$ average age of employees, variation coefficient of employees' age, number of occupational groups, industry sector, legal form, collective pay commitment, workers' council, downsizing, ${ }^{5}$ and a constant. $\gamma_{\mathrm{i}}$ describes a time constant, company specific effect. $u_{i t}$ is the error term.

By incorporating the interaction effects of the proportion of women in the workforce and the proportion of part-time positions as well as interactions between the female share and gender mainstreaming respectively formalism, we can flexibly model the direction of the relationship of these influencing factors and thus depict theoretically assumed interdependencies between the independent variables. ${ }^{6}$

2 By linearly transforming the corrected index, we can estimate fractional response models, which are characterized by the fact that the dependent variable is limited to the interval $[0 ; 1]$. We make use of the fact that the linear transformation of the dependent variable does not change the signs of the estimated coefficients. The transformation is carried out as follows:

$$
D I_{(i) C O R}=0.5+0.5 \cdot D I_{(i) c o r}
$$

3 The dummy variable is defined as 1 when the establishment was founded before 1990 .

4 A profession is defined as a male/female profession when at labor market level more than 70 percent of the employees in this profession are male/female.

5 Downsizing is defined as dummy variable, which takes the value 1 if the number of employees decreased by a minimum of 10 percent compared to the previous year.

6 To study the different directions of effect we have also estimated the models separately for establishments employing mostly white- collar or mostly blue-collar workers. If the ratio of blue-collar to white-collar workers was more than 60/40 (40/60), an establishment 
Regarding the estimation of our model, it should be noted that we cannot rule out that unobserved heterogeneity between the firms exists, for example in the form of the corporate culture. By using numerous control variables, we assume that the possibly existing endogeneity of the explaining variable is significantly reduced and that unobserved factors such as the corporate culture can be seen as time-constant in the period considered and are therefore captured by the company-specific effect $\gamma_{i}$. To account for the problem of time-constant unobserved heterogeneity, we use panel models which explicitly control for the company-specific individual effects.

The use of panel data combined with fixed-effects (FE) models could enable an unbiased estimation of our effects. However, only the within variation is used for the estimation of the coefficients, which is why no effects of time-constant variables can be estimated. The variables we use are organizational characteristics which predominantly show variation at the intercompany level. In contrast, we observe little variation within firms, as most organizational characteristics remain stable over time and show only few changes within a four-year period (e.g. industry and location only change in individual cases). The result is that some effects cannot be estimated and others only on the basis of a small number of cases with a variation over time. This results in high standard errors of the estimators and therefore missing significances. ${ }^{7}$ Random-effects (RE) models or pooled OLS regressions (POLS) remain the alternative to fixedeffects models, considering the unobserved heterogeneity. These are based on the analysis of intercompany differences and less on within variation, which the FE estimator uses. The problematic assumption for both estimation methods is, however, that the specific unobserved heterogeneity of the firms, i.e. the company-specific effect $\gamma_{i}$ must be exogenous. We cannot rule out that some of the regressors we use are correlated with unobserved characteristics. To the extent to which that is the case, it limits a purely causal interpretation of the estimated effects, which needs to be considered in the discussion of the results. We decided to use both POLS and RE under these constraints, but have included the result of the FE estimation in the appendix (see section 5.2).

A direct comparison of RE and POLS models shows that RE models under the validity of all assumptions estimate more efficiently than POLS. However, strict endogeneity is required as identifying assumption (cf. Cameron \& Trivedi, 2009). This assumption can become problematic in the framework of our estimations if we expect a serial correlation in the variables. This correlation structure might exist in our dataset, as we for example cannot rule out a relationship between the level of segregation in 2004 and the implementation of equality measures or formalized personnel recruitment processes in 2008. In this case POLS would be more suitable as it does not require the assumption of strict endogeneity. We have decided to juxtapose the two models.

was categorized as "blue collar" ("white collar"). The results do not show significant differences in the direction of effect of the explaining variable between the two sectors. However, the coefficients differ in strength. The results are available on demand.

7 see Table A2. 
Furthermore, we estimate the model presented above as panel fractional response (FR) model. This takes account of the fact that the dependent variable, i.e. the corrected dissimilarity index, is defined as continuous variable in the interval [0;1]. In the panel fractional response model a probit response function is calculated using a pooled Bernoulli quasi-maximum likelihood estimator (QMLE). We specify the correlation structure of the companies' unobserved heterogeneity with the other explaining variables analogous to the linear random effects model. The identifying assumption is therefore in turn that the unobserved heterogeneity is not correlated with the explaining variable. For details, see Wooldridge and Papke (2008).

\section{Data}

This study uses the cross-sectional model of the Linked-Employer-Employee Data (LIAB) (Version 2, Years 2004 and 2008) from the IAB. Data access was provided via on-site use at the Research Data Centre (FDZ) of the German Federal Employment Agency (BA) at the Institute for Employment Research (IAB) and subsequently remote data access. The LIAB data link process-generated personal data of the Federal Employment Agency and of the social security system to data from the IAB establishment panel (IABEP). The IABEP is a representative, disproportionately drawn random sample of establishments with at least one employee subject to social security contribution. The annual panel survey (reference date June 30) covers recurring information on size, workforce structure, or turnover but also alternating selected issues such as gender mainstreaming. The process data consist of employee and benefit notifications as of June 30 of persons, who at that time were employed by an establishment panel firm. Not included are therefore occupational groups such as selfemployed, civil servants, or those in minor employment. A detailed description of the data can be found in Heining, Scholz, and Seth (2013).

The LIAB offers the exceptional opportunity to analyze workforce characteristics in combination with business characteristics so that labor supply and labor demand can be viewed simultaneously. For the analysis at hand, the waves of 2004 and 2008 are used, as these waves of the IAB establishment panel contain additional questions concerning gender mainstreaming.

Our dataset is restricted to firms with more than 20 employees who are subject to social security contribution, the reason being that in smaller businesses, gender segregation is largely influenced by random fluctuations. For technical reasons, only firms with a workforce consisting of men and women and with more than one occupational group are included in the analysis. Table A1 shows the descriptive statistics of the dataset for the years 2004 and 2008. The weighting factors of the establishment panel were used for these and other descriptive analyses. The results are therefore an extrapolation for the German labor market.

\section{Empirical results}

\subsection{The extent of gender segregation in German firms}

On the basis of the LIAB, we have calculated the dissimilarity index in its form by Duncan and Duncan (1955) as well as the corrected index by Carrington and Troske (1997) at labor market and establishment level for the years 2004 and 2008. We meas- 
ure the (un)equal distribution of men and women across occupational groups. This grouping was done because the more refined the breakdown of occupations, the larger the extent of random segregation would be. For that purpose, we compile all threedigit occupational titles to two-digit ones, which leads us to a maximum of 65 occupational groups per establishment (see Table A1).

Table 1 provides an overview of the calculated values of the dissimilarity index at labor market level (DI, DI $\mathrm{Dor}_{\text {) }}$ ) and at establishment level $\left(\mathrm{DI}_{\mathrm{i}}, \mathrm{DI}_{\mathrm{i}, \mathrm{cor}}\right)$ in the years 2004 and 2008. At labor market level, the corrected DI yields a value of 0.5420 in the year 2004. With 0.4210 the value at establishment level is lower. Also in 2008, the segregation at labor market level is higher than at establishment level $(0.5186$ as opposed to 0.4082), measured by the corrected index. The comparison of the correction effect at labor market and establishment level shows that the higher segregation at establishment level measured by the uncorrected index can be explained with the higher random distribution within the small units: While the correction at labor market level effects only little change - here each occupational group is represented by large numbers of employees - the index drops substantially at establishment level with the correction.

Table 1: Overview of corrected and uncorrected dissimilarity indices at total labor market and establishment level by year

\begin{tabular}{|c|c|c|c|c|c|c|}
\hline & \multicolumn{3}{|c|}{2004} & \multicolumn{3}{|c|}{2008} \\
\hline & mean & $\begin{array}{l}\text { standard } \\
\text { deviation }\end{array}$ & $\mathrm{N}$ & mean & $\begin{array}{l}\text { standard } \\
\text { deviation }\end{array}$ & $\mathrm{N}$ \\
\hline DI & 0.5260 & 0 & 7326 & 0.5208 & 0 & 6616 \\
\hline $\mathrm{Dl}_{\mathrm{i}}$ & 0.5796 & 0.2852 & 7326 & 0.5695 & 0.2810 & 6616 \\
\hline $\mathrm{Dl}_{\text {cor }}$ & 0.5240 & 0 & 7326 & 0.5186 & 0 & 6616 \\
\hline $\mathrm{Dl}_{\mathrm{i}, \mathrm{cor}}$ & 0.4210 & 0.3766 & 7326 & 0.4082 & 0.3692 & 6616 \\
\hline
\end{tabular}

Source: LIAB Cross-sectional model 2004 and 2008, own calculations using weighting factors.

Our results correspond with the findings of previous empirical studies. Hinz and Schübel (2001), for example, who simply calculate the index in accordance with Duncan and Duncan, show that segregation is higher at the level of the establishment than on the labor market as a whole. However, the opposite emerges as soon as the corrected index is applied, as shown e.g. by Achatz et al. (2010).

Between 2004 and 2008, there was little change in the concentration of men and women in different occupations: We cannot determine any relevant changes over time, neither for the corrected, nor for the uncorrected index.

In order to explain the differences between companies in the level of segregation, we can first analyze the descriptively the distribution of the $\mathrm{DI}_{\mathrm{i} \text {,cor }}$ conditional on different organizational characteristics. It appears that the mean level of segregation varies systematically with organizational characteristics such as company size, industry sector, or location. Features of organizational demographics as well as the existence of formalized recruitment procedures and gender mainstreaming seem to be associated 
with the level of $\mathrm{DI}_{(\mathrm{cor})} \cdot{ }^{8}$ The dependence on the proportion of women in the workforce is worth noting: It is striking that with a very low proportion of women $(\leq 0.1)$, the segregation is substantially more distinct than with a very high proportion of women $(>0.9)$, even though there is the same asymmetry between the number of men and women. This can be interpreted as an indication that men integrate more easily in female occupations than women do in male occupations (cf. Achatz et al., 2010). Yet this example in particular reveals the weakness of the bivariate analysis: The proportion of women in the workforce is not independent of other business characteristics, such as e.g. the industry sector. A conclusion about the actual effects of the proportion of women in the workforce can therefore not be drawn based on only bivariate analysis.

\subsection{Estimation results}

The bivariate results are now to be verified by means of multivariate models. For that purpose, we estimate three model types: Pooled OLS, Random Effects, and Fractional Response. In each model the dependent variable is the linear transformation of the corrected dissimilarity index $\left(\mathrm{DI}_{\mathrm{i}, \mathrm{COR}}\right)$ at establishment level.

We compare the specification presented in section 3.2 with estimations result based on a functional form without interactions in the variables related to the proportion of women in the workforce. This specification is to illustrate which influence the non-linear modeling (i.e. using interactions) of the effects of the variables gender mainstreaming, formalism, and proportion of part-time has, compared with the model version used in previous studies, which only considers the stand alone effect of the variables. Table 2 provides an overview of the estimation results for the POLS, RE, and FR model. Columns (1) and (2) of Table 2 show the results of the POLS estimations. Columns (3), (4) and (5), (6) contain the estimation results for RE and FR models. Columns with uneven numbers show the specification without interactions and columns with even numbers show the model with interactions added.

We can see that particularly the relationship between segregation and the proportion of part-time is strongly context-sensitive, i.e. it differs depending on the proportion of women in the workforce. Without consideration of the interaction term, no significant effect can be shown in any of the models, as positive and negative effects are balanced in the total sample. Considering the interaction with the proportion of women in the workforce, all three models yield highly significant results. While in firms with a higher proportion of women, a higher proportion of part-time jobs is linked to significantly higher segregation, it leads towards integration in a maledominated environment. This corresponds exactly with the theoretical argumentation. Figure 1 shows that the coefficients of the proportion of women in the firm and the proportion of part-time jobs can only simultaneously be interpreted meaningfully and illustrates the relationship with regard to the marginal effects. 
Table 2: Estimation results of the POLS, RE, and FR models in different specifications

\begin{tabular}{|c|c|c|c|c|c|c|}
\hline & (1) & (2) & (3) & (4) & (5) & (6) \\
\hline VARIABLES & POLS & POLS & RE & RE & FR & FR \\
\hline \multirow[t]{2}{*}{ Year 2008} & -0.0021 & -0.0044 & $-0.0083^{* * *}$ & $-0.0087^{\star \star *}$ & $-0.0190^{\star \star *}$ & $-0.0223^{* * *}$ \\
\hline & $(0.0031)$ & $(0.003)$ & $(0.0023)$ & $(0.002)$ & $(0.0073)$ & $(0.007)$ \\
\hline \multirow[t]{2}{*}{$\begin{array}{l}\text { Proportion of } \\
\text { women (FS) }\end{array}$} & $-0.1639^{\star * \star}$ & $-0.2614^{\star \star \star}$ & $-0.1593^{\star \star \star}$ & $-0.2310^{\star * *}$ & $-0.4850^{\star *}$ & $-0.7764^{\star * \star}$ \\
\hline & $(0.0135)$ & $(0.017)$ & $(0.0135)$ & $(0.016)$ & $(0.0380)$ & $(0.047)$ \\
\hline \multirow[t]{2}{*}{$\begin{array}{l}\text { Gender } \\
\text { Mainstreaming }\end{array}$} & $-0.0081^{* * *}$ & $-0.0284^{\star \star *}$ & -0.0024 & $-0.0143^{\star \star \star}$ & $-0.0143^{\star \star}$ & $-0.0734^{\star \star *}$ \\
\hline & $(0.0030)$ & $(0.006)$ & $(0.0023)$ & $(0.004)$ & $(0.0073)$ & $(0.016)$ \\
\hline \multirow[t]{2}{*}{$\begin{array}{l}\text { Gender Main- } \\
\text { streaming x FS }\end{array}$} & - & $0.0483^{* * *}$ & - & $0.0282^{* * *}$ & - & $0.1309^{* * *}$ \\
\hline & & $(0.012)$ & & $(0.010)$ & & $(0.029)$ \\
\hline \multirow[t]{2}{*}{ Formalism } & $-0.0087^{* \star *}$ & $-0.0274^{\star \star \star}$ & $-0.0048^{*}$ & $-0.0195^{\star * *}$ & $-0.0199^{\star *}$ & $-0.0854^{* * *}$ \\
\hline & $(0.0032)$ & $(0.006)$ & $(0,0025)$ & $(0.004)$ & $(0.0079)$ & $(0.016)$ \\
\hline \multirow[t]{2}{*}{ Formalism x FS } & - & $0.0442^{\star \star *}$ & - & $0.0341^{* * *}$ & - & $0.1427^{\star \star *}$ \\
\hline & & $(0.012)$ & & $(0.011)$ & & $(0.032)$ \\
\hline \multirow[t]{2}{*}{ Part-time share } & 0.0020 & $-0.2079^{\star \star *}$ & -0.0011 & $-0.1562^{\star \star *}$ & 0.0058 & $-0.5902^{* \star *}$ \\
\hline & $(0.0099)$ & $(0.025)$ & $(0.0094)$ & $(0.025)$ & $(0.0256)$ & $(0.069)$ \\
\hline \multirow[t]{2}{*}{ Part-time share $x$ FS } & - & $0.3242^{\star \star \star}$ & - & $0.2397^{\star * *}$ & - & $0.9104^{\star * *}$ \\
\hline & & $(0.038)$ & & $(0.039)$ & & $(0.104)$ \\
\hline \multirow[t]{2}{*}{$\begin{array}{l}\text { Establishment } \\
\text { size(In) }\end{array}$} & $-0.0229^{\star * *}$ & $-0.0244^{* * \star}$ & $-0.0221^{\star * \star}$ & $-0.0231^{\star * *}$ & $-0.0658^{\star \star \star}$ & $-0.0691^{* * *}$ \\
\hline & $(0.0023)$ & $(0.002)$ & $(0.0023)$ & $(0.002)$ & $(0.0067)$ & $(0.007)$ \\
\hline \multirow[t]{2}{*}{$\begin{array}{l}\text { Age of } \\
\text { establishment }\end{array}$} & $0.0167^{\star \star \star}$ & $0.0169^{\star \star *}$ & $0.0131^{* \star *}$ & $0.0137^{* * *}$ & $0.0436^{* * *}$ & $0.0451^{* * *}$ \\
\hline & $(0.0039)$ & $(0.004)$ & $(0.0035)$ & $(0.004)$ & $(0.0107)$ & $(0.011)$ \\
\hline \multirow[t]{2}{*}{ East Germany } & $0.0212^{\star \star \star}$ & $0.0197^{\star \star \star}$ & $0.0163^{\star * *}$ & $0.0155^{\star * *}$ & $0.0521^{* \star *}$ & $0.0491^{* * *}$ \\
\hline & $(0.0041)$ & $(0.004)$ & $(0.0041)$ & $(0.004)$ & $(0.0120)$ & $(0.012)$ \\
\hline \multirow[t]{2}{*}{ Top share } & $0.1172^{\star *}$ & $0.1224^{\star \star *}$ & $0.0989^{\star * *}$ & $0.1022^{\star * *}$ & $0.2801^{* * *}$ & $0.2932^{\star * *}$ \\
\hline & $(0.0455)$ & $(0.045)$ & $(0.0365)$ & $(0.037)$ & $(0.1087)$ & $(0.109)$ \\
\hline \multirow[t]{2}{*}{ Top share ${ }^{2}$} & $-0.3178^{* *}$ & $-0.3387^{\star *}$ & $-0.2865^{\star \star}$ & $-0.2970^{* *}$ & $-0.7630^{* *}$ & $-0.8126^{* *}$ \\
\hline & $(0.1466)$ & $(0.145)$ & $(0.1187)$ & $(0.120)$ & $(0.3471)$ & $(0.349)$ \\
\hline \multirow[t]{2}{*}{ Top share ${ }^{3}$} & $0.1981^{*}$ & $0.2110^{* *}$ & $0.1861^{* *}$ & $0.1920^{\star *}$ & $0.4832^{\star *}$ & $0.5126^{* *}$ \\
\hline & $(0.1044)$ & $(0.104)$ & $(0.0844)$ & $(0.085)$ & $(0.2462)$ & $(0.248)$ \\
\hline Observations & 9087 & 9087 & 9087 & 9087 & 9087 & 9087 \\
\hline R-squared & 0.3975 & 0.4088 & & & & \\
\hline
\end{tabular}

Standard errors in parentheses

Source: LIAB Cross-sectional model 2004 and 2008, own calculations. Level of significance: ${ }^{*} p<0.1,{ }^{* *} p<0.05,{ }^{* * \star} p<0.01$. All models control for industry sector, legal form, share of employees in typical male/female occupations, average and variation coefficient of employees' age, number of occupational groups, collective pay commitment, workers' council and downsizing, share of graduates among employees and among female employees. 
Figure 1 shows on the vertical axis the proportion of part-time positions, on the horizontal axis the proportion of women in the workforce. We can see that the colored patterns on the right and left edges of the figure run in opposite directions. It can be interpreted that with a lower proportion of women in the workforce (e.g. $<20$ percent) an increase in the proportion of part-time jobs lowers the segregation. With a higher proportion (e.g. $>80$ percent) an increase in part-time employment goes conversely along with an increase of the corrected dissimilarity index.

Figure 1: Estimated effect of the implementation of equal opportunity measures on the corrected dissimilarity index in relation to the proportion of women

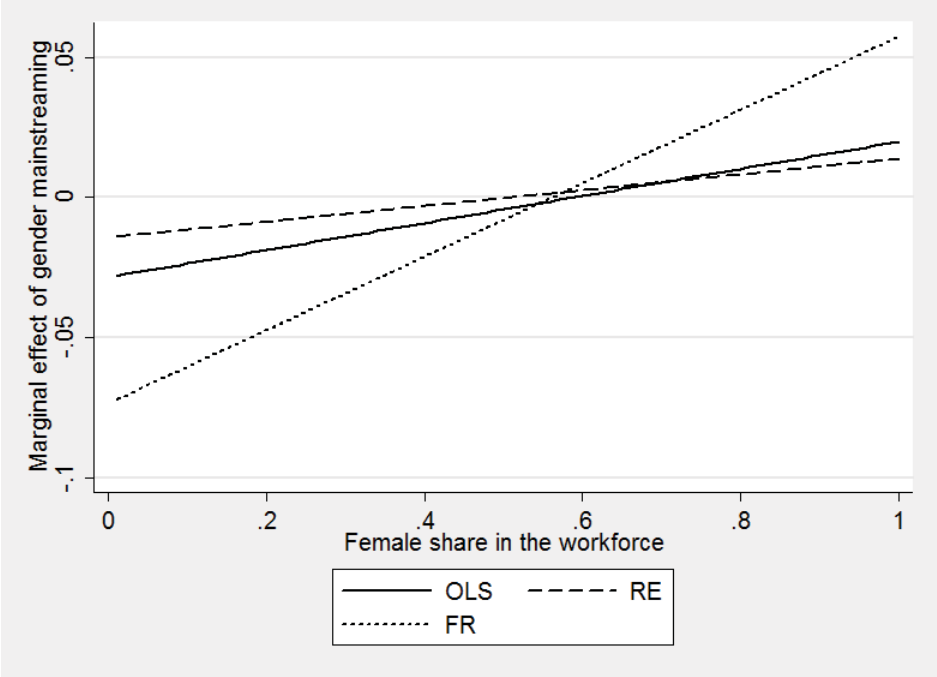

Source: LIAB 2004 and 2008, own calculation.

Figure 1 shows on the vertical axis the proportion of part-time positions, on the horizontal axis the proportion of women in the workforce. We can see that the colored patterns on the right and left edges of the figure run in opposite directions. It can be interpreted that with a lower proportion of women in the workforce (e.g. $<20$ percent) an increase in the proportion of part-time jobs lowers the segregation. With a higher proportion (e.g. $>80$ percent) an increase in part-time employment goes conversely along with an increase of the corrected dissimilarity index.

For the coefficients of the variables gender mainstreaming and formalism the interaction with the proportion of women in the workforce also proves highly significant in all three estimation procedures. We find a significant effect of the implementation of gender mainstreaming on the corrected dissimilarity index, which varies depending on the female share in an establishment. Figure 2 shows these dependencies.

The estimation results show that in companies with a proportion of women of less than 60 percent, gender mainstreaming go along with a lesser extent of segregation. However, the marginal effect becomes positive with a higher proportion of women. 
Figure 2: Estimated effect of formalism on the corrected dissimilarity index in relation to the proportion of women

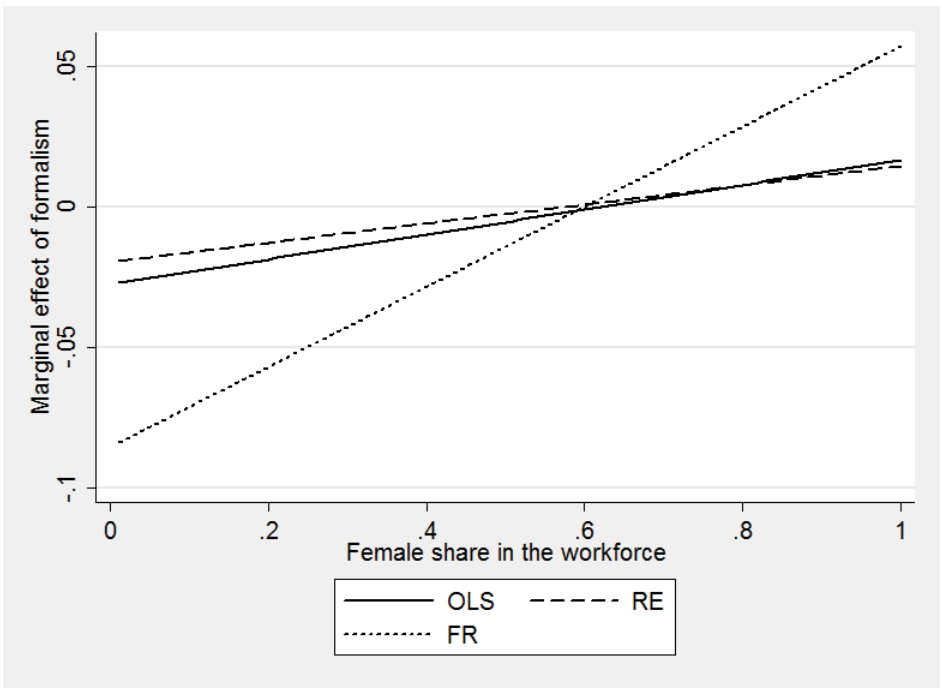

Source: LIAB 2004 and 2008, own calculation.

Figure 3: Estimated effect of part-time share in the context of the proportion of women in the workforce on the corrected dissimilarity index in the POLS model

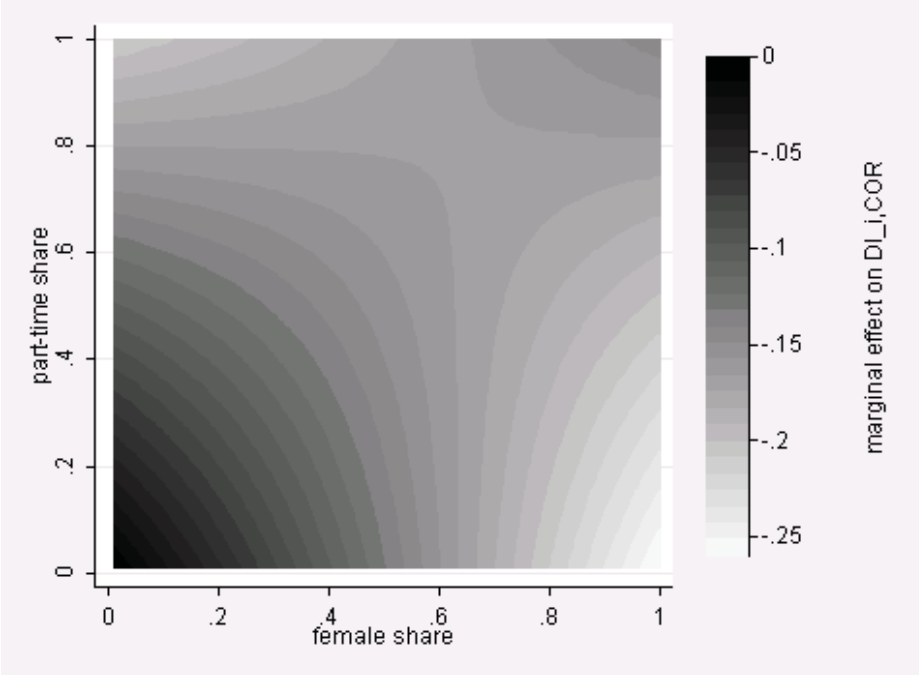

Source: LIAB 2004 and 2008, own calculation.

Figure 3 shows furthermore that the marginal effect for formalized processes in personnel selection (formalism) is also context-sensitive. In all estimations, we find a significant influence of these formalized processes. By interacting these dummy variables with the proportion of women in the workforce again a mixed picture emerges: Formalized processes in personnel selection correspond to a lower level of segregation 
when applied in businesses with less than 60 percent women in the workforce. However, when the proportion of women in the labor force is higher, a significantly higher value of the corrected dissimilarity index is found when formalized processes exist in personnel selection just like with gender mainstreaming. These insights can be interpreted to mean that the existence of gender mainstreaming as well as formalized processes in personnel selection ease women's entry into male-dominated companies.

Yet it has to be considered in the interpretation that when it comes to the marginal effects of the three influencing factors discussed above that a high proportion of women in the workforce (FS) is associated with a significantly lower value of the corrected dissimilarity index. The extent of the correlation is to be regarded as dominant for the total sample compared with the other estimated coefficients. The results nevertheless suggest that the implementation of gender mainstreaming and formalized processes in personnel selection are organizational characteristics that can be changed in the short term; yet they can also be used as a lever for the reduction of segregation. Moreover, the proportion of part-time employees in particular shows a close, though not linear relationship to the level of segregation within a company.

Figure 4: Estimated effect of the top share on the corrected dissimilarity index

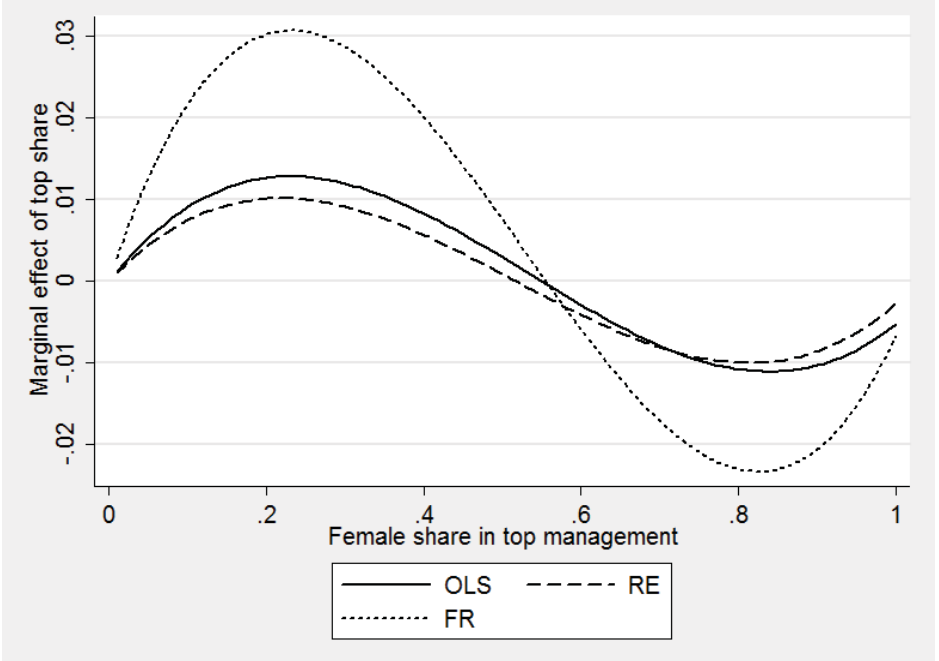

Source: LIAB 2004 and 2008, own calculation.

To estimate the influence of vertical segregation, we utilize the proportion of women at top management level in firms (top share). We model the effect of the proportion of women in top management as a third-degree polynomial and show a significant correlation. The estimations show that an increase in the proportion of women in management positions at low base level is linked to higher segregation. However, when a certain percentage of women in management positions is attained, this is associated with a lower level of segregation (see Fig. 4). This can also be seen as evidence for theoretical studies saying that the appointment of individual women into management positions is strategically employed to feign a successful integration of 
minorities, in this case women (see Kanter, 1977 for details). The size of the estimated coefficient for vertical segregation is comparable with the one for the female share in the workforce.

Corresponding to our theoretical considerations, we also find a positive estimated coefficient for the age of the organization and a significant correlation with the age structure in the company. In accordance with previous studies, we also find a significantly negative effect of the firmsize on the corrected dissimilarity index, a significantly higher level of segregation in East German companies, and significant differences by industry sectors (not reported). We can thus validate the previous empirical studies with our results. Moreover, by expanding the examination with regard to contextsensitive relationships, particularly the proportion of part-time jobs as well as formalized processes and gender mainstreaming, we can contribute to a better understanding of differences in the level of segregation in German firms.

The results discussed above prove stable across the estimation models POLS, RE, and FR (cf. Table 2). ${ }^{9}$ It shows that the results of the POLS estimations are robust and do not differ considerably from FR and RE. As already discussed theoretically, the validity of the identification assumptions of all three models must be questioned critically. From a theoretical point of view, an FE model should be preferred to the RE model in order to consider a potential correlation between company-specific unobserved heterogeneity with the explaining variables. As indicated in section 4, the estimation of FE models did not prove useful because of the data we used. Many of the variables used in the estimation are - apart from individual cases - time-constant at firm level (e.g. industry sector, location, year of company foundation). For timevariable parameters, particularly the implementation of formalized processes and gender mainstreaming, changes can only be observed in a small proportion of the firms (less than 15 percent of the sample ${ }^{10}$ ). For these firms, we can furthermore assume that this change possibly has no directly measurable effect on the level of segregation yet, as this becomes visible only in the long run with a change in recruitment policy and which can therefore be captured better via inter-company differences. The possibilities of the FE estimation are therefore limited and show no significant estimators because of the low intra firm variation. The results of the FE estimation can be found in Table A2. ${ }^{11}$

Table 2 shows the estimated coefficients of the FR model. The calculation of marginal effects yields results comparable to the RE coefficients.

10 Detailed statistics on the variation of the variables over time are available upon request.

11 In the case of the non-linear fractional response model, the problem discussed above can be met by using time averages of all variables as additional covariates (see Wooldridge and Papke, 2008). Yet because of the low variation over time in the data we used, this is also not promising and leads to non-significant results because of the missing variation. The results of the specification are available upon request. 


\section{Summary and conclusion}

This article describes the extent of horizontal occupational segregation in German firms on the basis of the LIAB datasets of the years 2004 and 2008 and analyzes the relationships between the extent of horizontal segregation and organizational characteristics. The consistently high level of segregation in Germany and the identification of potential levers in firms for its reduction are of high scientific as well as sociopolitical relevance, as horizontal gender segregation is not only accompanied by differences in the distribution of the sexes across occupational groups, but also leads to inequalities in wage, status and career opportunities. We calculate the dissimilarity index in accordance with Duncan and Duncan (1955) to measure the extent of horizontal segregation in the German labor market and within firms and use Carrington and Troske's correction method (1997) to control random fluctuations in the gender ratio of small occupational groups.

Using panel data models, we estimate the influence of different organizational characteristics on the segregation within the firms. In accordance with existing studies, we find a relationship between the extent of horizontal segregation and establishment size, industry, and legal form. We can also show that organizational demographics significantly influence the level of segregation; the critical influencing factors are the proportion of women in the workforce and the proportion of part-time employees in particular. Another central aspect of our analysis is human resource measures and their interdependencies with other organizational characteristics. We find a significant negative influence of human resource measures such as the implementation of gender mainstreaming and formalized recruitment procedures on the horizontal segregation of the establishment. Out estimations show a lower level of segregation in firms where these measures are implemented. Yet it shows that these effects are context-sensitive and reduce segregation only in those firms that have less than 60 percent women in their workforce. These results show that the adoption of human resource measures with the aim of reducing segregation must be discussed in the context of other organizational characteristics. It seems that the implementation of gender mainstreaming or formalized recruitment procedures only provide a "lead in" for women in maledominated firms. Companies and politics can use this finding to assess potential measures for the reduction of segregation.

Finally, we examine the relationship of horizontal and vertical segregation: The multivariate models suggest that there is no linear relationship between a low proportion of women at management level and a segregated workforce, but that only beyond a critical threshold of a 20 percent proportion of women in management positions, is there a lower level of segregation in the firm. This relationship is particularly interesting in the course of the debate about a compulsory women's quota. If more women are to get into management positions, an integrated workforce can be the basis for increasing the proportion of women in management. This, however, requires further analyses in order to identify the direction of the relationship between horizontal and vertical segregation and possibly additional determinants of this relationship.

Overall, our article shows that the extent of horizontal segregation in German firms differs substantially and that these differences occur systematically according to 
organizational characteristics. It can therefore be concluded that certain company characteristics either reinforce or reduce segregation. In contrast to, for example, location or industry, the existence of human resource instruments such as gender mainstreaming or formalized recruitment routines can be changed in the short term. They therefore represent influencing factors that can be utilized as levers for changing the level of segregation in the firm.

\section{References}

Achatz, J. (2008). Die Integration von Frauen in Arbeitsmärkten und Organisationen. In S. M. Wilz (ed.), Geschlechterdifferenzen - Geschlechterdifferenఇierungen. Ein Überblick über gesellschaftliche Entwicklungen und theoretische Positionen (pp. 105-138). Wiesbaden: VS Verlag für Sozialwissenschaften.

Achatz, J., Beblo, M., \& Wolf, E. (2010). Berufliche Segregation. In Projektgruppe GiB (eds.), Geschlecbterungleichbeiten im Betrieb. Arbeit, Entlohnung und Gleichstellung in der Privatwirtschaft (pp. 89-140). Berlin: Edition Sigma.

Acker, J. (1990). Hierarchies, jobs, bodies: A theory of gendered organizations. Gender and Society, 4, 139158

Allmendinger, J., \& Podsiadlowski, A. (2001). Segregation in Organisationen und Arbeitsgruppen. In B. Heintz (ed.), Geschlechtersoziologie (pp. 276-307). Wiesbaden: Westdeutscher Verlag.

Bansak, C., Graham, M.E., \& Zebedee, A.A. (2012). Business cycles and gender diversification: An analysis of establishment-level gender dissimilarity. American Economic Review, 102(3), 561-65.

Beblo, M., Heinze, A., \& Wolf, E. (2008). Entwicklung der beruflichen Segregation von Männern und Frauen zwischen 1996 und 2005 - Eine Bestandsaufnahme auf betrieblicher Ebene. Zeitschrift für Arbeitsmarktforschung, 41(2/3), 181-198.

Bielby, W.T., \& Baron, J.N. (1980). Bringing the firms back in: Stratification, segmentation, and the organization of work. American Sociological Review, 45(5), 737-765.

Blackburn, M.R., Browne, J., Brooks, B., \& Jarman, J. (2002). Explaining gender segregation. British Journal of Sociology, 53(4), 513-536.

Blau, F.D., Brummund, P., \& Liu, A.Y.-H. (2012). Trends in occupational segregation by gender 19702009: Adjusting for the impact of changes in the occupational doding System. IZA Discussion Paper 6490 , Institute for the Study of Labor (IZA).

Busch, A. (2013). Die berufliche Geschlechtersegregation in Deutschland: Ursachen, Reproduktion, Folgen. Wiesbaden: Springer VS.

Cameron, A.C., \& Trivedi, P.K. (2009). Microeconometrics: Methods and applications. Cambridge: Cambridge University Press.

Carrington, W.J., \& Troske, K.R. (1997). On measuring segregation in samples with small units. Journal of Business and Economic Statistics, 15(4), 402-409.

Duncan, O.D., \& Duncan, B. (1955). A methodological analysis of segregation indexes. American Sociological Review, 20(2), 210-217.

EUCOM (2010). Report on equality between women and me. Office for Official Publications of the European Communities. European Commission (EUCOM).

Falk, S. (2002). Geschlechtsspezifische berufliche Segregation in Ostdeutschland zwischen Persistenz, Verdrängung und Angleichung: ein Vergleich mit Westdeutschland für die Jahre 1991-2000. Mitteilungen aus der Arbeitsmarkt- und Berufforschung, 32(1), 37-59.

Flückiger, Y., \& Silber, J. (1999). The measurement of segregation in the labor force. Heidelberg: Physica.

Handl, J. (1984). Chancengleichheit und Segregation: Ein Vorschlag zur Messung ungleicher Chancenstrukturen und ihrer zeitlichen Entwicklung. Zeitschrift für Soziologie, 13(4), 328-345.

Heining, J., Scholz, T., \& Seth, S. (2013). Linked-employer-employee data from the IAB: LIAB crosssectional model 2 1993-2010 (LIAB QM2 9310). FDZ-Datenreport Nr. 02/2013. Nürnberg.

Hinz, T., \& Gartner, H. (2009). Geschlechtsspezifische Lohnungleichheit in Betrieben, Berufen und Jobzellen (1993-2006). Berliner Journal für Soziologie, 19(4), 557-575. 
Hinz, T., \& Schübel, T. (2001). Geschlechtersegregation in deutschen Betrieben. Mitteilungen aus der Arbeitsmarkt- und Berufsforschung, 34(3), 286-301.

Jürges, H., \& Schneider, K. (2011). Why young boys stumble: Early tracking, age and gender bias in the German school system. German Economic Review 12(4), 371-394.

Kanter, R. M. (1977). Men and women at corporation. New York: Basic Books.

Lee, C., \& Farh, J.-L. (2004). Joint effects of group efficacy and gender diversity on group cohesion and performance. Applied Psychology, 53(1), 136-154.

Ludsteck, J. (2014). The impact of segregation and sorting on the gender wage gap - Evidence from German linked longitudinal employer-employee data. Industrial and Labor Relations Review, 67(2), 362394.

OECD (2012). Closing the gender gap: Act now. Paris: OECD Publishing.

Reskin, B.F., \& McBrier, D.B. (2000). Why not ascription? Organizations' employment of male and female managers. American Sociological Review, 65(2), 210-233.

Seifert, S., \& Schlenker, E. (2014). Berufliche Geschlechtersegregation auf Betriebsebene in Deutschland. In U. Busolt, S. Weber, W. Kronsbein \& C. Wiegel (eds.), Karriereverläufe in Forschung und Entwicklung - Bedingungen und Perspektiven im Spannungsfeld von Organisation und Individuum (pp. 90-109). Berlin: Logos Verlag.

Sieben, B., \& Bornheim, N. (2011). Intersektionalität und Diversity - Achsen der Differenz in Managementkonzepten und Managementförderung. In S. Smykalla \& D. Vinz (eds.), Intersektionalität zwischen Gender und Diversity (pp. 93-110). Münster: Westfälisches Dampfboot.

Stainback, K., \& Kwon, S. (2011). Female leaders, organizational power, and sex segregation. The ANNALS of the American Academy of Political and Social Science, 639(1), 217-233.

Tomaskovic-Devey, D., \& Skaggs, S. (2001). Führt Bürokratisierung zu geschlechtsspezifischer Segregation? In B. Heintz (ed.), Geschlechtersoziologie (pp. 308-331). Wiesbaden: Westdeutscher Verlag.

Trappe, H., \& Rosenfeld, R. (2001). Geschlechtsspezifische Segregation in der DDR und der BRD: Im Verlauf der Zeit und im Lebensverlauf. In B. Heintz (ed.), Geschlechtersoziologie (pp. 152-181). Wiesbaden: Westdeutscher Verlag.

Wooldridge, J.M., \& Papke, L.E. (2008). Panel data methods for fractional response variables with an application to test pass rates. Journal of Econometrics, 145(1), 121-133. 


\section{Appendix}

Table A1: Descriptive statistics of the panel dataset

\begin{tabular}{|c|c|c|c|c|c|}
\hline & mean & standard deviation & minimum & maximum & $\mathrm{N}$ \\
\hline $\mathrm{Dl}_{\mathrm{i}, \mathrm{COR}}$ & 0.705 & 0.159 & 0.020 & 1 & 9087 \\
\hline Year (2008) & 0.510 & 0.500 & 0 & 1 & 9087 \\
\hline Gender Mainstreaming & 0.446 & 0.497 & 0 & 1 & 9087 \\
\hline Formalism & 0.624 & 0.484 & 0 & 1 & 9087 \\
\hline Female share & 0.442 & 0.271 & 0.001 & 0.996 & 9087 \\
\hline Part-time share & 0.204 & 0.221 & 0.001 & 1 & 9087 \\
\hline$\%$ male occupations & 0.400 & 0.330 & 0 & 1 & 9087 \\
\hline$\%$ female occupations & 0.236 & 0.314 & 0 & 1 & 9087 \\
\hline No. of occup. groups & 12.971 & 8.526 & 2 & 65 & 9087 \\
\hline Establishment size(In) & 4.844 & 1.182 & 3.045 & 10.780 & 9087 \\
\hline \multicolumn{6}{|l|}{ Industry } \\
\hline 2 & 0.023 & 0.150 & 0 & 1 & 9087 \\
\hline 3 & 0.032 & 0.175 & 0 & 1 & 9087 \\
\hline 4 & 0.034 & 0.180 & 0 & 1 & 9087 \\
\hline 5 & 0.095 & 0.293 & 0 & 1 & 9087 \\
\hline 6 & 0.148 & 0.355 & 0 & 1 & 9087 \\
\hline 7 & 0.033 & 0.180 & 0 & 1 & 9087 \\
\hline 8 & 0.094 & 0.291 & 0 & 1 & 9087 \\
\hline 9 & 0.037 & 0.190 & 0 & 1 & 9087 \\
\hline 10 & 0.039 & 0.194 & 0 & 1 & 9087 \\
\hline 11 & 0.014 & 0.118 & 0 & 1 & 9087 \\
\hline 12 & 0.043 & 0.204 & 0 & 1 & 9087 \\
\hline 13 & 0.118 & 0.322 & 0 & 1 & 9087 \\
\hline 14 & 0.095 & 0.293 & 0 & 1 & 9087 \\
\hline 15 & 0.029 & 0.168 & 0 & 1 & 9087 \\
\hline 16 & 0.023 & 0.149 & 0 & 1 & 9087 \\
\hline 17 & 0.130 & 0.336 & 0 & 1 & 9087 \\
\hline \multicolumn{6}{|l|}{ Industry } \\
\hline 2 & 0.022 & 0.148 & 0 & 1 & 9087 \\
\hline 3 & 0.570 & 0.495 & 0 & 1 & 9087 \\
\hline 4 & 0.068 & 0.251 & 0 & 1 & 9087 \\
\hline 5 & 0.214 & 0.410 & 0 & 1 & 9087 \\
\hline 6 & 0.101 & 0.301 & 0 & 1 & 9087 \\
\hline Age of organization & 0.648 & 0.478 & 0 & 1 & 9087 \\
\hline East Germany & 0.342 & 0.474 & 0 & 1 & 9087 \\
\hline Share of graduates & 0.138 & 0.192 & 0 & 1 & 9087 \\
\hline Share of female grad. & 0.121 & 0.186 & 0 & 1 & 9087 \\
\hline Collective pay comm. & 0.703 & 0.457 & 0 & 1 & 9087 \\
\hline Workers' council & 0.670 & 0.470 & 0 & 1 & 9087 \\
\hline Downsizing & 0.097 & 0.296 & 0 & 1 & 9087 \\
\hline Top share & 0.146 & 0.286 & 0 & 1 & 9087 \\
\hline Average age & 41.973 & 4.216 & 19.417 & 55.452 & 9087 \\
\hline Variation coeff. Age & 0.258 & 0.054 & 0.063 & 0.520 & 9087 \\
\hline
\end{tabular}

Source: LIAB cross-sectional model 2004 and 2008, own calculation. 
Table A2: Estimation results FE model

\begin{tabular}{|c|c|}
\hline & FE \\
\hline \multirow[t]{2}{*}{ Year 2008} & $-0.0140^{* * *}$ \\
\hline & $(0.0033)$ \\
\hline \multirow[t]{2}{*}{ Female share (FS) } & $-0.1388^{\star *}$ \\
\hline & $(0.0567)$ \\
\hline \multirow[t]{2}{*}{ Gender Mainstreaming } & 0.0030 \\
\hline & $(0.0052)$ \\
\hline \multirow[t]{2}{*}{ Gender Mainstreaming x FS } & 0.0010 \\
\hline & $(0.0125)$ \\
\hline \multirow[t]{2}{*}{ Formalism } & -0.0056 \\
\hline & $(0.0057)$ \\
\hline \multirow[t]{2}{*}{ Formalism $\times$ FS } & 0.0122 \\
\hline & $(0.0155)$ \\
\hline \multirow[t]{2}{*}{ Part-time share } & 0.0041 \\
\hline & $(0.0477)$ \\
\hline \multirow[t]{2}{*}{ Part-time share $x \mathrm{FS}$} & 0.0054 \\
\hline & $(0.0825)$ \\
\hline \multirow[t]{2}{*}{ Establishment size (In) } & -0.0070 \\
\hline & $(0.0090)$ \\
\hline \multirow[t]{2}{*}{ Age of organization } & 0.0058 \\
\hline & $(0.0059)$ \\
\hline \multirow[t]{2}{*}{ East Germany } & 0.0150 \\
\hline & $(0.0150)$ \\
\hline \multirow[t]{2}{*}{ Top share } & $0.0972^{* *}$ \\
\hline & $(0.0462)$ \\
\hline \multirow[t]{2}{*}{ Top share ${ }^{2}$} & $-0.3232^{* *}$ \\
\hline & $(0.1509)$ \\
\hline \multirow[t]{2}{*}{ Top share $^{3}$} & $0.2241^{* *}$ \\
\hline & $(0.1070)$ \\
\hline Observations & 9087 \\
\hline R-squared & 0.0555 \\
\hline
\end{tabular}

Source: LIAB cross-sectional model, own calculation. Level of significance: ${ }^{*} p<0.1,{ }^{* *} p<0.05,{ }^{* * *} p<0.01$. Controlled for industry sector, legal form, share of employees in typical male/female occupations, average and variation coefficient of employees' age, number of occupational groups, collective pay commitment, workers' council and downsizing, share of graduates among employees and among female employees. 